\title{
Mixture Proportion Design Method of Steel Fiber Reinforced Recycled Coarse Aggregate Concrete
}

\author{
Danying Gao ${ }^{1}$, Lijuan Zhang ${ }^{1, * \mathbb{C}}$, Michelle Nokken ${ }^{2} \mathbb{D}$ and Jun Zhao ${ }^{1} \mathbb{( D )}$ \\ 1 School of Mechanics and Engineering Science, Zhengzhou University, No.100 Science Avenue, \\ Zhengzhou 450001, China; gdy@zzu.edu.cn (D.G.); zhaoj@zzu.edu.cn (J.Z.) \\ 2 Faculty of Engineering and Computer Science, Concordia University, 1455 de Maisonneuve, West, \\ Ontreal H3G1M8, QC, Canada; m.nokken@concordia.ca \\ * Correspondence: zhanglj0526@zzu.edu.cn; Tel.: +86-136-5381-8353
}

Received: 23 December 2018; Accepted: 22 January 2019; Published: 25 January 2019

\begin{abstract}
Steel fiber reinforced recycled coarse aggregate concrete (SFRCAC) is an impact minimisation building material. Mixture proportion design method of SFRCAC is developed in this paper to obtain concrete with target strength and workability, which can be used in structural members. Four key parameters of mixture proportioning, steel fiber content, water-cement ratio, water content and sand ratio are discussed through the mixture design tests. The formula for calculating the four key parameters of mixture proportions for SFRCAC are established through the statistical analysis of test results, which mainly consider the influences of recycled coarse aggregate (RCA) replacement ratio and steel fiber characteristic coefficient. The detailed procedure by using the new mixture proportion design method is illustrated with examples. The formulas established have the simple form, reflect the properties of RCA and steel fibers, enhance the mixture proportion design accuracy, and provide the reference for the mix proportion design of SFRCAC.
\end{abstract}

Keywords: recycled aggregate concrete; steel fiber; mixture proportion design; water-cement ratio; water content; sand ratio

\section{Introduction}

Recycled coarse aggregate (RCA) presents a sustainable solution to the depletion of natural coarse aggregate (NCA) resources, and plays a key role in reducing the need for landfilling the waste disposal [1-4]. Because RCA is mainly composed of two different materials, NCA and the attached cement mortar [5,6], it has much higher water absorption and lower apparent density $[7,8]$. As well, a large number of micro cracks are produced in the crushing process of waste concrete, which causes the higher crushing index and reduces the soundness of RCA.

Due to the poor properties, the application of RCA has been limited. Adding steel fibers to recycled coarse aggregate concrete (RCAC) can provide the bridging effect to prevent and reduce the development of inherent micro-defects in RCAC [9], improve the mechanical properties of the RCAC and especially better control its fracture process [10-12]. It has been well established that the incorporation of steel fibers improves the engineering performance of RCAC, including better crack resistance, increasing ductility and toughness as well as the enhancement in resistance to fatigue and impact [13]. Also, steel fiber reinforced recycled aggregate concrete has better strength and durability than recycled aggregate concrete, it can extend the service life of construction, the combination of steel fibers and RCA has great environmental and economic benefits [14]. Hence, steel fiber reinforced recycled coarse aggregate concrete (SFRCAC) has great potential for use in structural member.

The methods for the mixture design of SFRCAC is the basis of material research as well as engineering application. The mixture proportions, such as varying coarse aggregate and steel fiber 
contents, will lead to the different properties of cement-based materials. Previous studies about the mixture proportion of RCAC mostly focus on the following aspects:

1. The effect of RCA on concrete strength. RCA may lead to 20-25\% decrease in compressive strength compared to NCA with the same mixture proportion [15-18]. The compressive strength of RCAC depends on the RCA properties and RCA replacement ratio $[19,20]$. All strength grades of RCA are suitable to produce low strength concrete $(20 \mathrm{MPa})$, but, the production of medium (40 MPa) and high strength $(60 \mathrm{MPa})$ concrete requires the RCA to have a source strength matching or exceeding the strength of the new concrete [3].

2. The method to adjust the water content of RCAC. The water absorption and cement mortar of RCA can be reduced by surface modification or pre-soaking methods $[7,21]$, both the pre-saturation method and the mixing water compensation method can be adopted to mix RCAC [22]. For the latter, a two-stage mixing approach divides the mixing process into two parts and proportionally splits the required water into two, this method has been found to improve the strength of RCAC $[23,24]$. However, the methods mentioned above only make some adjustments of water content in the batching process and do not provide the suitable calculation method for water content of RCAC.

3. The equivalent mortar volume method [25]. This method considers RCA as a two-phase material including mortar and NCA. The mixture design principle is the quantity and quality of each phase of RCAC should achieve the same total mortar volume with NCAC, but the calculation process of the method is too complicated to be easily used by engineers. A new mixture design method was put forward by taking into account the higher porosity of RCAs, but now it's only in conceptual and the RCA replacement ratio can't reach 100\% [26].

Although ACI-555R [27] provides the guidelines for proportioning of concrete mixtures made with RCA, neither it nor any other source gives a specific mixture design method for achieving target fresh and hardened properties for SFRCAC. Therefore, to obtain a specific and effective mixture design method for SFRCAC to ensure it has the similar fresh and hardened properties as conventional NCAC even if using the different RAC replacement ratios is the main aim of this study. The calculating formulas of steel fiber content, water-cement ratio, water content and sand ratio are proposed by extensive experiments and analysis.

\section{Materials and Methods}

\subsection{Materials}

Portland cement (P.O 42.5) conforming to the stipulation in GB 175 [28] was used in all mixtures. The coarse aggregate included NCA and RCA. NCA was crushed limestone with continuous grading of particle sizes from $4.75 \mathrm{~mm}$ to $20 \mathrm{~mm}$. RCA was obtained from the waste commercial ready-mixed concrete in a concrete testing station with the compressive strength ranging from $30 \mathrm{MPa}$ to $50 \mathrm{MPa}$, and unknown age. The waste concrete was collected and crushed through a jaw crusher, then screened through sieves with a maximum size of $20 \mathrm{~mm}$ and a minimum size of $4.75 \mathrm{~mm}$. The grading of the NCA and RCA was within the upper and lower limit bounds of ASTM C33 [29] except that the particle size distribution was in the percentage passing the $9.5 \mathrm{~mm}$ sieve, and $24 \%$ for NCA, $35 \%$ for RCA. The fine aggregate was river sand with a fineness modulus of 2.67. The properties of all aggregates used in the test are shown in Table 1. The test was carried out according to Chinese standard GB/T 25177 [30] and GB/T 14685 [31]. The test method of crush index is pressuring the coarse aggregate with the size from $9.5 \mathrm{~mm}$ to $19 \mathrm{~mm}$ which is put into the specified modulus to $200 \mathrm{kN}$ with the speed of $1 \mathrm{kN} / \mathrm{s}$, and then the mass of these coarse aggregate which size is below $2.36 \mathrm{~mm}$ is measured and the crush index was calculated. Crush index mainly reflects the soundness of coarse aggregate. It can be seen from Table 1 that the crush index of RCA is much higher than NCA, it means that the soundness of RCA is poorer than NCA. The void ratio of coarse aggregate is calculated by the difference between 
their apparent density and bulk density. The void ratio mainly reflecting the compactness of coarse aggregate, the higher of the void ratio, the poorer of compactness of coarse aggregate. It can be seen from Table 1 that the void ratio of RCA is higher than NCA.

Table 1. Physical properties of the coarse and fine aggregate.

\begin{tabular}{|c|c|c|c|c|c|c|}
\hline$\underset{\text { Type }}{\text { Aggregate }}$ & $\begin{array}{c}\text { Apparent } \\
\text { Density } \\
\left(\mathrm{kg} / \mathrm{m}^{3}\right)\end{array}$ & $\begin{array}{c}\text { Loose Packing } \\
\text { Density } \\
\left(\mathrm{kg} / \mathrm{m}^{3}\right)\end{array}$ & $\begin{array}{c}\text { Dry-Rodded } \\
\text { Density } \\
\left(\mathrm{kg} / \mathrm{m}^{3}\right)\end{array}$ & $\begin{array}{c}\text { Water } \\
\text { Absorption } \\
\text { (wt. \%) }\end{array}$ & $\begin{array}{l}\text { Crush Index } \\
(\%)\end{array}$ & $\begin{array}{c}\text { Void Ratio } \\
\text { (\%) }\end{array}$ \\
\hline RCA & 2640 & 1302 & 1412 & 4.85 & 17.7 & 50.3 \\
\hline NCA & 2814 & 1568 & 1630 & 1.40 & 8.8 & 44.3 \\
\hline Sand & 2556 & 1611 & 1486 & 0.56 & - & - \\
\hline
\end{tabular}

Compared with the NCA, the RCA had higher water absorption, void ratio and crushing index, but lower apparent density. All aggregates used were in the oven-dry condition. Three types of steel fiber were used in this study, the photos and characteristics of steel fibers are shown in Table 2.

Table 2. Photos and characteristics of steel fibers.

\begin{tabular}{|c|c|c|c|}
\hline Steel Fiber Type & MF & WF & HF \\
\hline \multicolumn{4}{|l|}{ Fiber photo } \\
\hline Mean length $\left(1_{f}\right) / \mathrm{mm}$ & 32.3 & 30 & 62 \\
\hline Mean diameter $\left(d_{f}\right) / \mathrm{mm}$ & 0.94 & 0.76 & 0.75 \\
\hline Aspect ratio $\left(1_{f} / d_{f}\right)$ & 34.2 & 39.7 & 82.3 \\
\hline
\end{tabular}

\subsection{Mixture Proportion Method}

The research objective of this paper is to precisely determine the mixture design parameters of SFRCAC to achieve the target strength and workability. Generally, the conventional concrete is mainly composed of natural coarse aggregate, sand, cement and water. The key mixture design parameters for concrete include water-cement ratio $(\mathrm{W} / \mathrm{C})$, water content $\left(m_{\mathrm{w}}\right)$ and sand ratio $\left(\beta_{\mathrm{s}}\right)$. Once these parameters are determined, each component can be calculated by forecast quality method or absolute volume method [32].

Compared with conventional concrete, the properties and amounts of RCA and steel fiber will inevitably affect the mechanical properties and workability of SFRCAC. Therefore, how to determine the effect of RCA and steel fiber on the mixture design parameters is the first problem to be solved. The experiments in this paper was divided into four parts and the test parameters used in the test are listed in Table 3.

Table 3. Test plan and parameters.

\begin{tabular}{|c|c|c|c|c|c|c|c|}
\hline \multirow{2}{*}{ Test Parameters } & \multicolumn{3}{|c|}{ Material Parameters } & \multicolumn{3}{|c|}{ Mixture Design Parameters } & \multirow{2}{*}{$\begin{array}{c}\text { Assessment } \\
\text { Criteria }\end{array}$} \\
\hline & $\begin{array}{l}\text { Steel Fiber } \\
\text { Type }\end{array}$ & $V_{\mathrm{f}}$ & $r_{\mathrm{g}}$ & W/C & $m_{\mathrm{w}}$ & $\beta_{\mathrm{s}}$ & \\
\hline Steel fiber content & $\mathrm{MF} / \mathrm{WF} / \mathrm{HF}$ & $0-2 \%$ & $0,100 \%$ & 0.48 & $164-196$ & $36 \%$ & $f_{\mathrm{ftm}}$ \\
\hline Water-cement ratio & none & - & $0,50 \%, 100 \%$ & $0.30-0.55$ & 180 & $36 \%$ & $f_{\mathrm{cu}}$ \\
\hline Water content & $\mathrm{MF} / \mathrm{HF}$ & $0-2 \%$ & $0,50 \%, 100 \%$ & 0.40 & $160-220$ & $36 \%$ & slump \\
\hline Sand content & MF & $0-2 \%$ & $0,50 \%, 100 \%$ & 0.40 & 190 & New method & $f_{\text {cu, slump }}$ \\
\hline
\end{tabular}


According to the test purpose, the whole test was divided into the following four parts:

1. The purpose of the first part was the determination of the steel fiber content. Steel fibers have more significant effect on the flexural strength than compressive strength [33], hence, the volume fraction of steel fiber $\left(V_{\mathrm{f}}\right)$ can be determined by the flexural strength achieved. In order to ensure the workability of SFRCAC, for each increase in $V_{\mathrm{f}}$ of $0.5 \%$, the water content is increased by $8 \mathrm{~kg} / \mathrm{m}^{3}$ and the sand ratio by $3 \%$ [34]. To accurately determine the reinforcement effect of steel fibers on flexural strength, one mixture of the plain concrete without steel fibers made with the same mixture proportion corresponding to each $V_{\mathrm{f}}$ group of SFRCAC was also prepared. The mixture designs used in this part are listed in Table 4.

Table 4. Mixture design $\left(\mathrm{kg} / \mathrm{m}^{3}\right)$ and flexural strength of steel fiber reinforced recycled coarse aggregate concrete (SFRCAC) with different steel fiber.

\begin{tabular}{cccccccc}
\hline Specimen No. & Water & Cement & Sand & NCA & RCA & Steel Fiber & $f_{\text {ftm }} / \mathbf{M P a}$ \\
\hline R0 & 164 & 342 & 721 & 1283 & 0 & 0 & 5.90 \\
R100 & 164 & 342 & 721 & 0 & 1283 & 0 & 4.46 \\
R0MF0.5 & 172 & 358 & 749 & 1171 & 0 & 39 & 6.67 \\
R0NF0.5-C & 172 & 358 & 749 & 1171 & 0 & 0 & 5.71 \\
R100MF0.5 & 172 & 358 & 749 & 0 & 1171 & 39 & 5.00 \\
R100NF0.5-C & 172 & 358 & 749 & 0 & 1171 & 0 & 4.79 \\
R0MF1.0 & 180 & 375 & 796 & 1099 & 0 & 78 & 7.28 \\
R0HF1.0 & 180 & 375 & 796 & 1099 & 0 & 78 & 16.25 \\
R0WF1.0 & 180 & 375 & 796 & 1099 & 0 & 78 & 8.13 \\
R0NF1.0-C & 180 & 375 & 796 & 1099 & 0 & 0 & 5.78 \\
R100MF1.0 & 180 & 375 & 796 & 0 & 1099 & 78 & 5.44 \\
R100HF1.0 & 180 & 375 & 796 & 0 & 1099 & 78 & 14.07 \\
R100WF1.0 & 180 & 375 & 796 & 0 & 1099 & 78 & 5.73 \\
R100NF1.0-C & 180 & 375 & 796 & 0 & 1099 & 0 & 4.79 \\
R0MF1.5 & 188 & 392 & 842 & 1029 & 0 & 117 & 8.76 \\
R0NF1.5-C & 188 & 392 & 842 & 1029 & 0 & 0 & 6.59 \\
R100MF1.5 & 188 & 392 & 842 & 0 & 1029 & 117 & 7.36 \\
R100NF1.5-C & 188 & 392 & 842 & 0 & 1029 & 0 & 5.53 \\
R0MF2.0 & 196 & 408 & 886 & 960 & 0 & 156 & 9.27 \\
R0NF2.0-C & 196 & 408 & 886 & 960 & 0 & 0 & 5.65 \\
R100MF 2.0 & 196 & 408 & 886 & 0 & 960 & 156 & 8.54 \\
R100NF2.0-C & 196 & 408 & 886 & 0 & 960 & 0 & 4.34 \\
\hline
\end{tabular}

Note: R100MF1.0 stands for the specimen with $r_{\mathrm{g}}$ of $100 \%$, milling steel fiber and $V_{\mathrm{f}}$ of $1.0 \%$; R100NF1.0-C is the plain concrete which has the same mix proportion with R100F1.0.

2. The water-cement ratio $(\mathrm{W} / \mathrm{C})$ is the parameter influence concrete strength in mixture design. Previous research has shown that using the same $\mathrm{W} / \mathrm{C}$, the addition of the steel fiber does significantly improve the compressive strength of concrete after 28 days [35], but RCA may lead to $20-25 \%$ decreasing of compressive strength [15]. The properties and replacement ratio of RCA have significant effect on the strength of SFRCAC. The relation between compressive strength $\left(f_{\mathrm{cu}}\right)$ and $\mathrm{W} / \mathrm{C}$ was studied in this part; RCA replacement ratio $\left(r_{\mathrm{g}}\right)$, which is the mass ratio of the RCA to the total coarse aggregate, was taken as $0 \%, 50 \%$ and $100 \%$. Due to the differences in density of NCA and RCA, the quantity of aggregate and sand was increasing with the increase of $\mathrm{W} / \mathrm{C}$ in the mixing process. The mixture designs used in this part are listed in Table 5. 
Table 5. Mixture design $\left(\mathrm{kg} / \mathrm{m}^{3}\right)$ and compressive strength of recycled coarse aggregate concrete (RCAC) with different water-cement ratio $(\mathrm{W} / \mathrm{C})$.

\begin{tabular}{ccccccc}
\hline Specimen No. & Water & Cement & Sand & NCA & RCA & $f_{\text {cu }} / \mathbf{M P a}$ \\
\hline W/C0.3R0 & 180 & 600 & 603 & 1073 & 0 & 75.2 \\
W/C 0.3R50 & 180 & 600 & 590 & 525 & 525 & 58.4 \\
W/C0.3R100 & 180 & 600 & 579 & 0 & 1030 & 55.3 \\
W/C0.35R0 & 180 & 514 & 630 & 1121 & 0 & 62.0 \\
W/C0.35R50 & 180 & 514 & 617 & 549 & 549 & 59.6 \\
W/C0.35R100 & 180 & 514 & 605 & 0 & 1076 & 55.9 \\
W/C0.4R0 & 180 & 450 & 650 & 1157 & 0 & 56.4 \\
W/C0.4R50 & 180 & 450 & 636 & 566 & 566 & 51.3 \\
W/C0.4R100 & 180 & 450 & 624 & 0 & 1111 & 49.2 \\
W/C0.45R0 & 180 & 400 & 666 & 1185 & 0 & 47.5 \\
W/C0.45R50 & 180 & 400 & 652 & 580 & 580 & 45.7 \\
W/C0.45R100 & 180 & 400 & 639 & 0 & 1138 & 41.6 \\
W/C0.5R0 & 180 & 360 & 678 & 1207 & 0 & 43.6 \\
W/C0.5R50 & 180 & 360 & 664 & 591 & 591 & 41.2 \\
W/C0.5R100 & 180 & 360 & 651 & 0 & 1160 & 37.4 \\
W/C0.55R0 & 180 & 327 & 689 & 1226 & 0 & 38.2 \\
W/C0.55R50 & 180 & 327 & 674 & 600 & 600 & 35.3 \\
W/C0.55R100 & 180 & 327 & 661 & 0 & 1177 & 34.2 \\
\hline
\end{tabular}

Note: W/C0.45R50 stands for the specimen with $\mathrm{W} / \mathrm{C}$ of 0.45 and $r_{\mathrm{g}}$ of $50 \%$.

3. Slump is an index reflecting the workability of concrete, which mainly was affected by the water content of concrete. The accurate determination for the water content of SFRCAC with different RCA and steel fibers to achieve target slump is the objective of this part. More water is required in the batching process to obtain the similar slump for RCAC as NCAC due to the higher water absorption of RCA $[21,36,37]$. The slump of concrete has been found to decrease with the increase of aspect ratio and volume fraction of steel fiber [38]. In this part, the several mixtures were made at each water content varying both $r_{\mathrm{g}}$ and $V_{\mathrm{f}}$, as shown in Table 6 .

Table 6. Mixture design $\left(\mathrm{kg} / \mathrm{m}^{3}\right)$ and compressive strength of steel fiber reinforced recycled coarse aggregate concrete (SFRCAC) with different water content.

\begin{tabular}{ccccccccc}
\hline Specimen No. & Water & \multicolumn{2}{c}{ Cement Sand } & NCA & RCA & Steel Fiber & Slump/mm & $f_{\text {cu }} / \mathbf{M P a}$ \\
\hline W16R0 & 160 & 400 & 685 & 1210 & 0 & 0 & 6 & 47.8 \\
W16R50 & 160 & 400 & 671 & 597 & 597 & 0 & 4 & 45.5 \\
W16R100 & 160 & 400 & 658 & 0 & 1171 & 0 & 2 & 45.0 \\
W17R0 & 170 & 425 & 668 & 1187 & 0 & 0 & 13 & 51.9 \\
W17R50 & 170 & 425 & 654 & 582 & 582 & 0 & 7 & 48.2 \\
W17R100 & 170 & 425 & 642 & 0 & 1141 & 0 & 5 & 45.7 \\
W18R0 & 180 & 450 & 650 & 1157 & 0 & 0 & 32 & 56.4 \\
W18R50 & 180 & 450 & 636 & 566 & 566 & 0 & 21 & 51.3 \\
W18R100 & 180 & 450 & 624 & 0 & 1111 & 0 & 13 & 49.2 \\
W19R0 & 190 & 475 & 632 & 1126 & 0 & 0 & 60 & 49.6 \\
W19R0MF1.0 & 190 & 475 & 632 & 1126 & 0 & 78 & 53 & 48.9 \\
W19R0HF1.0 & 190 & 475 & 632 & 1126 & 0 & 78 & 42 & 50.6 \\
W19R0MF2.0 & 190 & 475 & 632 & 1126 & 0 & 156 & 44 & 51.0 \\
W19R0HF2.0 & 190 & 475 & 632 & 1126 & 0 & 156 & 25 & 52.2 \\
W19R50 & 190 & 475 & 619 & 551 & 551 & 0 & 46 & 48.1 \\
W19R50MF1.0 & 190 & 475 & 619 & 551 & 551 & 78 & 40 & 49.2 \\
W19R50HF1.0 & 190 & 475 & 619 & 551 & 551 & 78 & 32 & 50.5 \\
W19R50MF2.0 & 190 & 475 & 619 & 551 & 551 & 156 & 34 & 50.7 \\
W19R50HF2.0 & 190 & 475 & 619 & 551 & 551 & 156 & 18 & 50.2 \\
W19R100 & 190 & 475 & 607.3 & 0 & 1081 & 0 & 29 & 47.2 \\
W19R100MF1.0 & 190 & 475 & 607 & 0 & 1081 & 78 & 25 & 48.6 \\
W19R100HF1.0 & 190 & 475 & 607 & 0 & 1081 & 78 & 20 & 49.0 \\
\hline
\end{tabular}


Table 6. Cont.

\begin{tabular}{ccccccccc}
\hline Specimen No. & Water & \multicolumn{2}{c}{ Cement Sand } & NCA & RCA & Steel Fiber & Slump/mm & $f_{\text {cu }} / \mathbf{M P a}$ \\
\hline W19R100MF2.0 & 190 & 475 & 607 & 0 & 1081 & 156 & 22 & 50.1 \\
W19R100HF2.0 & 190 & 475 & 607 & 0 & 1081 & 156 & 10 & 51.3 \\
W20R0 & 200 & 500 & 615 & 1094 & 0 & 0 & 96 & 50.2 \\
W20R50 & 200 & 500 & 602 & 536 & 536 & 0 & 78 & 48.7 \\
W20R100 & 200 & 500 & 590 & 0 & 1051 & 0 & 49 & 51.2 \\
W21R0 & 210 & 525 & 597 & 1063 & 0 & 0 & 130 & 47.4 \\
W21R50 & 210 & 525 & 585 & 521 & 521 & 0 & 121 & 46.4 \\
W21R100 & 210 & 525 & 574 & $0 / 0$ & 1020 & 0 & 106 & 46.0 \\
W22R0 & 220 & 550 & 580 & 1032 & 0 & 0 & 175 & 47.2 \\
W22R50 & 220 & 550 & 568 & 505 & 505 & 0 & 168 & 44.5 \\
W22R100 & 220 & 550 & 557 & 0 & 991 & 0 & 159 & 42.8 \\
\hline
\end{tabular}

Note: W19R50HF1.0 stands for the specimen with water content of $190\left(\mathrm{~kg} / \mathrm{m}^{3}\right), r_{\mathrm{g}}$ of $50 \%$, hooked at both ends steel fiber, and $V_{\mathrm{f}}$ of $1.0 \%$.

4. The sand ratio $\left(\beta_{\mathrm{s}}\right)$ is the mass ratio of sand to the total mass of aggregates (the mass sum of sand and coarse aggregate). Generally, $\beta_{\mathrm{s}}$ is chosen according to the experience for ordinary concrete [33]. Now, there is no precise calculation formula of $\beta_{\mathrm{s}}$ for SFRCAC. The determination of a reasonable sand ratio for SFRCAC was studied in this part. According to the principle that fine aggregate needs to fill the voids between coarse aggregates, the volume of sand required in SFRCAC should be the sum of voids caused by all coarse aggregates (including NCA and RCA) and the dispersal of steel fibers. Hence, a new calculation model of sand volume can be set up as follows:

$$
V_{\mathrm{s}}=\gamma \times\left(V_{\text {na }} \times P_{\text {na }}+V_{\text {ra }} \times P_{\text {ra }}+V_{\mathrm{f}}\right)
$$

where, $\gamma$ is the sand rich coefficient, it is the volume ratio between the fine aggregate and the void caused by coarse aggregate and steels fiber, the range of $\gamma$ can be taken from 1.1 to 1.4 for NCAC [39], and can also be determined by tests; $P_{\text {na }}$ is the void ratio of NCA, $P_{\text {ra }}$ is the void ratio of RCA, both $P_{\text {na }}$ and $P_{\text {ra }}$ are the basic material properties of coarse aggregate and can be obtained by tests; $V_{\mathrm{f}}$ is the volume fraction of steel fibers used to represent the voids caused by steel fibers, because the void caused by steel fibers should be less than the volume of steel fibers in the common use range of $0-2 \%$ and rarely more than $4 \%$. The sand content can be calculated by Equation (1), the values of other mixture design parameters in this part are consistent with the previous parts. Table 7 gives the mixture designs in this part.

Table 7. Mixture proportions $\left(\mathrm{kg} / \mathrm{m}^{3}\right)$ and test results for new sand content method.

\begin{tabular}{cccccccccc}
\hline Specimen No. & Water & Cement & Sand & NCA & RCA & Steel Fiber & $\beta_{\mathbf{s}}$ & Slump/mm & $f_{\text {cu }} / \mathbf{M P a}$ \\
\hline CR0MF0 & 190 & 475 & 622.8 & 1106 & 0 & 0 & 36 & 64 & 50.4 \\
CR50MF0 & 190 & 475 & 648.3 & 521 & 521 & 0 & 38.4 & 58 & 51.6 \\
CR100MF0 & 190 & 475 & 673.2 & 0 & 987.4 & 0 & 40.8 & 50 & 51.2 \\
CR0MF0.5 & 190 & 475 & 629 & 1085 & 0 & 39 & 36.7 & 60 & 50.9 \\
CR50MF0.5 & 190 & 475 & 655.7 & 511.7 & 511.7 & 39 & 39 & 57 & 51.1 \\
CR100MF0.5 & 190 & 475 & 678 & 0 & 968.2 & 39 & 41.2 & 48 & 51.5 \\
CR0MF1.0 & 190 & 475 & 634 & 1064 & 0 & 78 & 37.3 & 60 & 51.2 \\
CR50MF1.0 & 190 & 475 & 660 & 502 & 502 & 78 & 39.7 & 53 & 52.3 \\
CR100MF1.0 & 190 & 475 & 683.8 & 0 & 949.6 & 78 & 41.9 & 43 & 52.6 \\
CR0MF1.5 & 190 & 475 & 641 & 1044 & 0 & 117 & 38 & 55 & 53.3 \\
CR50MF1.5 & 190 & 475 & 667 & 492 & 492 & 117 & 40.4 & 50 & 52.1 \\
CR100MF1.5 & 190 & 475 & 689.1 & 0 & 931 & 117 & 42.5 & 40 & 52.9 \\
CR0MF2.0 & 190 & 475 & 647 & 1023 & 0 & 156 & 38.7 & 52 & 54.5 \\
CR50MF2.0 & 190 & 475 & 670.8 & 482.2 & 482.2 & 156 & 41 & 45 & 53.7 \\
CR100MF2.0 & 190 & 475 & 693.7 & 0 & 912.4 & 156 & 43.2 & 38 & 53.2 \\
\hline
\end{tabular}

Note: CR50MF1.0 stands for the specimen with $r_{\mathrm{g}}$ of $50 \%$, milling steel fiber and $V_{\mathrm{f}}$ of $1.0 \%$. 
When the material and mixture design parameters were determined, the "absolute volume method" was chosen to calculate the components of SFRCAC because the changing range of RCA density is bigger than NCA, which leads to the weight per cubic meter of SFRCAC is difficult to estimate. The dosage of each component of SFRCAC can be calculated by:

$$
\begin{gathered}
V_{\mathrm{c}}+V_{\mathrm{w}}+V_{\mathrm{s}}+V_{\mathrm{na}}+V_{\mathrm{ra}}+V_{\mathrm{f}}+\alpha=1 \\
r_{\mathrm{g}}=\frac{m_{\mathrm{ra}}}{m_{\mathrm{ra}}+m_{\mathrm{na}}}=\frac{\rho_{\mathrm{ra}} \times V_{\mathrm{ra}}}{\rho_{\mathrm{ra}} \times V_{\mathrm{ra}}+\rho_{\mathrm{na}} \times V_{\mathrm{na}}} \Rightarrow \frac{V_{\mathrm{na}}}{V_{\mathrm{ra}}}=\frac{\left(1-r_{\mathrm{g}}\right) \times \rho_{\mathrm{ra}}}{r_{\mathrm{g}} \times \rho_{\mathrm{na}}} \\
\beta_{\mathrm{s}}=\frac{m_{\mathrm{s}}}{m_{\mathrm{s}}+m_{\mathrm{na}}+m_{\mathrm{ra}}}=\frac{\rho_{\mathrm{s}} V_{\mathrm{s}}}{\rho_{\mathrm{s}} V_{\mathrm{s}}+\rho_{\mathrm{na}} V_{\mathrm{na}}+\rho_{\mathrm{ra}} V_{\mathrm{ra}}}
\end{gathered}
$$

where, $V_{\mathrm{c}}, V_{\mathrm{w}}, V_{\mathrm{s}}, V_{\mathrm{na}}, V_{\mathrm{ra}}$ and $V_{\mathrm{f}}$ is the volume of cement, water, sand, NCA, RCA and steel fibers, respectively; $m_{\mathrm{s}}, m_{\mathrm{na}}$ and $m_{\mathrm{ra}}$ are the mass of sand, NCA and RCA, respectively; $\rho_{\text {na }}$ and $\rho_{\text {ra }}$ are the apparent density of sand, NCA and RCA, respectively; $\alpha$ is the air content, to non-air-entrained steel fiber concrete, $\alpha=0.02$.

\subsection{Specimen Preparation and Test}

The cubic specimens with side length of $150 \mathrm{~mm}$ were cast for the compressive strength $\left(f_{\mathrm{cu}}\right)$ test, the prism specimens of $100 \mathrm{~mm} \times 100 \mathrm{~mm} \times 400 \mathrm{~mm}$ were cast for flexural strength $\left(f_{\mathrm{ftm}}\right)$ test, in which the three specimens for each group were prepared. The mixing process included three steps. Firstly, the suitable moulds were prepared and brushed inside with a release agent. Secondly, all aggregates and steel fibers were put into a small mixer to mix for about $2 \mathrm{~min}$ to ensure that steel fibers could be uniformly distributed in the aggregates. Thirdly, the cement was added, and mixing continued for another minute. Finally, the water was added to the mixer slowly, and mixed for another $2 \mathrm{~min}$.

The slump of fresh SFRCAC was tested first, then was put into the prepared moulds and vibrated for $20 \mathrm{~s}$. After $24 \mathrm{~h}$ curing in ambient temperature, the specimens were carefully demoulded and placed in a curing room at approximately $95 \% \mathrm{RH}$ and $20^{\circ} \mathrm{C}$.

All the tests were conducted after the 28-days curing of specimens. The compressive tests were performed according to the stipulation in GB/T50081 [40], and were carried on a servo-hydraulic closed-loop testing machine with capacity of $3000 \mathrm{kN}$ at the loading rate of $0.6 \mathrm{MPa} / \mathrm{s}$. The flexural tests were carried on a MTS810 testing machine with capacity of $500 \mathrm{kN}$, displacement control at a rate of $0.1 \mathrm{~mm} / \mathrm{min}$, according to ASTM C1609 (Using Beam With Third-Point Loading) [41]. The test results of each group are the mean value of test results for three specimens. The test results in this research are listed in Tables $4-7$, respectively.

\section{Analysis and Discussion}

\subsection{Steel Fiber Content}

Based on the experimental results in Table 4, the flexural strength increases as $V_{\mathrm{f}}$ increases from 0 to $2 \%$, regardless if $r_{\mathrm{g}}=0$ or $r_{\mathrm{g}}=100 \%$. This indicates that the higher the $V_{\mathrm{f}}$, the better the reinforcing effect of steel fiber on flexural strength. Because the fibers of MF and WF have similar aspect ratios, the effect of MF and WF on the flexural strength of RCAC and NCAC is quite similar. The aspect ratio of $\mathrm{HF}$ is much higher than MF and WF, and consequently the flexural strength and reinforcement ratio of $\mathrm{HF}$ is much higher.

According to the analysis mentioned above, the volume fraction $\left(V_{\mathrm{f}}\right)$ and aspect ratio $\left(l_{\mathrm{f}} / d_{\mathrm{f}}\right)$ of steel fibers have much influence on the flexural strength of RCAC, which can be comprehensively reflected by steel fiber characteristic coefficient $\left(\lambda_{\mathrm{f}}\right)$, where $\lambda_{\mathrm{f}}=V_{\mathrm{f}} l_{\mathrm{f}} / d_{\mathrm{f}}$. The relation of the flexural strength ratio of SFRCAC to RCAC with steel fiber characteristic coefficient, based on the experimental 
data from this paper and previous literature [42], is shown in Figure 1, an equation is put forward as follows:

$$
f_{\mathrm{ftm}} / f_{\mathrm{tm}}=\alpha_{\mathrm{f}} \lambda_{\mathrm{f}}^{2}+\beta_{\mathrm{f}}
$$

where, $f_{\mathrm{ftm}}$ is the flexural strength of SFRCAC, MPa; $f_{\mathrm{tm}}$ is the flexural strength of RCAC which has the same mix proportion corresponding to SFRCAC, MPa; $\alpha_{\mathrm{f}}$ and $\beta_{\mathrm{f}}$ are the parameters related to material properties, here, $\alpha_{\mathrm{f}}=2.5, \beta_{\mathrm{f}}=1$.

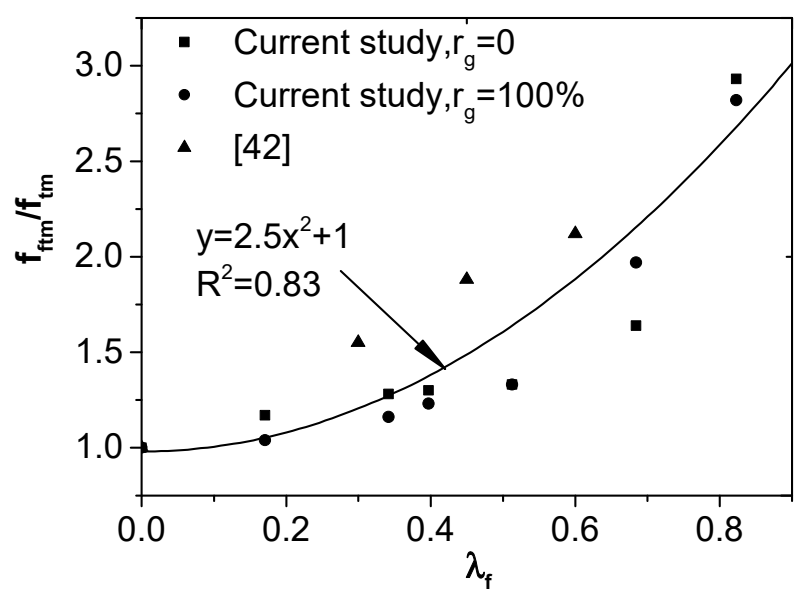

Figure 1. Relation between $f_{\mathrm{ftm}} / f_{\mathrm{tm}}$ and $\lambda_{\mathrm{f}}$.

The steel fiber characteristic coefficient can be calculated by Equation (5) for the required flexural strength of SFRCAC, then the steel fiber volume fraction can be determined after choosing the appropriate steel fiber type and aspect ratio.

\subsection{Water-Cement Ratio}

The compressive strength test results of RCAC with different $\mathrm{W} / \mathrm{C}$ are listed in Table 5. Obviously, the compressive strength $f_{\mathrm{cu}}$ of RCAC decreases with the increase of $r_{\mathrm{g}}$ at the same $\mathrm{W} / \mathrm{C}$ because the quality of the RCA is lower than NCA as stated in many previous studies $[6,15,43,44]$.

For the RCAC with $r_{\mathrm{g}}$ of $50 \%$ or $100 \%$ and W/C of above $0.35, f_{\text {cu }}$ increases continuously with the decrease of $\mathrm{W} / \mathrm{C}$, but for the RCAC with $\mathrm{W} / \mathrm{C}$ of below $0.35, f_{\mathrm{cu}}$ decreases slightly with the decrease of W/C. This is different from the NCAC with $r_{\mathrm{g}}$ of $0 \%$, where $f_{\text {cu }}$ decreases continuously with the increase of $\mathrm{W} / \mathrm{C}$. This is because that the failure of RCAC is caused by the damage of weak point inherited from crushed RCA rather than the damage of cement mortar when $\mathrm{W} / \mathrm{C}$ is below 0.35 and compressive strength is higher than $50 \mathrm{MPa}$. Therefore, the compressive strength of RCAC is mainly limited by the strength of RCA instead of W/C. Previous studies have had the similar conclusions $[3,16]$. Consequently, the weakest point in concretes made with RCA of medium-high strength $(45-60 \mathrm{MPa})$ could be determined by the strength of RCA or the adhered mortar $[3,16]$.

Based on the stipulation in Chinese Standards JGJ55 [32], the first step in mixture design is to determine the $\mathrm{W} / \mathrm{C}$ according to the target compressive strength by using the following equation:

$$
f_{\mathrm{cu}, 0}=\alpha_{\mathrm{a}} f_{\mathrm{ce}}\left(C / W-\alpha_{\mathrm{b}}\right)
$$

where $f_{\mathrm{cu}, 0}$ is the cubic compressive strength of concrete at 28 days, $\mathrm{MPa} ; f_{\mathrm{ce}}$ is the compressive strength of cement at 28 days, $\mathrm{MPa} ; \mathrm{W} / \mathrm{C}$ is the cement-water ratio; $\alpha_{\mathrm{a}}$ is the cement strength conversion coefficient; $\alpha_{\mathrm{b}}$ is the virtual cement-water ratio. $\alpha_{\mathrm{a}}$ and $\alpha_{\mathrm{b}}$ are dependent on the quality and type of coarse aggregate. When the coarse aggregate is gravel, $\alpha_{\mathrm{a}}=0.53, \alpha_{\mathrm{b}}=0.2$; when the coarse aggregate is pebble, $\alpha_{\mathrm{a}}=0.49, \alpha_{\mathrm{b}}=0.13$.

When $\mathrm{W} / \mathrm{C}$ changes from 0.35 to 0.55 , the relation between the ratio of RCAC compressive strength to cement compressive strength $f_{\mathrm{cu}} / f_{\mathrm{ce}}$ and $\mathrm{C} / \mathrm{W}$ is shown in Figure 2 , in which the solid 
points stand for the test results. It is clear that $f_{\mathrm{cu}} / f_{\mathrm{ce}}$ is proportional to $\mathrm{C} / \mathrm{W}$ for the RCAC with the constant of $r_{\mathrm{g}}$, which abides by the principle of Equation (6). The values of $\alpha_{\mathrm{a}}$ and $\alpha_{\mathrm{b}}$ for SFRCAC with different $r_{\mathrm{g}}$ can be obtained through the regression analysis of the experimental data, that is $\alpha_{\mathrm{a}}=0.53$ and $\alpha_{\mathrm{b}}=0.2$ for $r_{\mathrm{g}}=0 \% ; \alpha_{\mathrm{a}}=0.502$ and $\alpha_{\mathrm{b}}=0.217$ for $r_{\mathrm{g}}=50 \% ; \alpha_{\mathrm{a}}=0.476$ and $\alpha_{\mathrm{b}}=0.244$ for $r_{\mathrm{g}}=100 \%$.

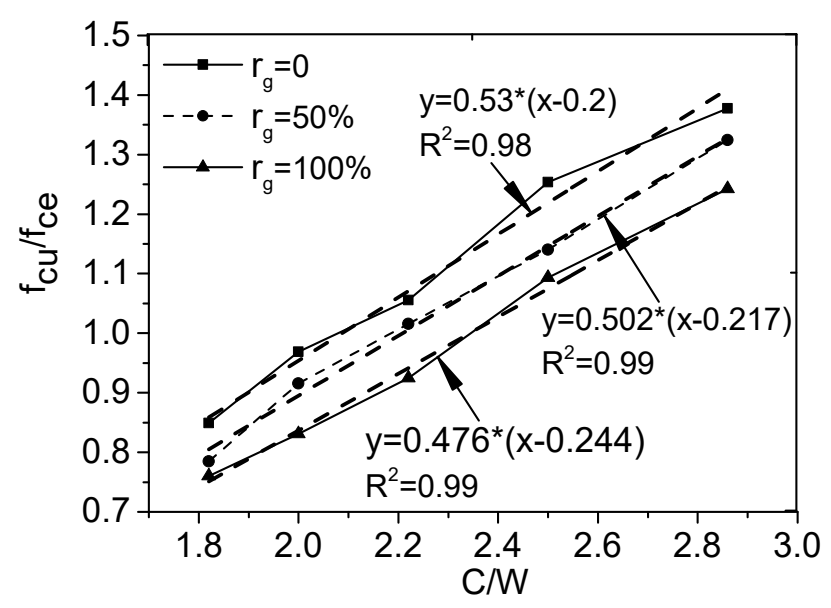

Figure 2. Relation between $f_{\mathrm{cu}} / f_{\mathrm{ce}}$ and $\mathrm{C} / \mathrm{W}$.

The quality of the coarse aggregate used in RCAC is not only related to the property of RCA, but also $r_{\mathrm{g}}$. Generally, the quality of the RCA is weaker than NCA, $\alpha_{\mathrm{a}}$ decreases and $\alpha_{\mathrm{b}}$ increases with the increase of $r_{\mathrm{g}}$, respectively. Therefore, the relation of $\alpha_{\mathrm{a}}, \alpha_{\mathrm{b}}$ with $r_{\mathrm{g}}$ can be expressed as follows:

$$
\begin{gathered}
\alpha_{\mathrm{a}}=0.53\left(1-\alpha_{\mathrm{c}} \times r_{\mathrm{g}}\right) \\
\alpha_{\mathrm{b}}=0.2\left(1+\alpha_{\mathrm{d}} \times r_{\mathrm{g}}\right)
\end{gathered}
$$

where, $\alpha_{\mathrm{c}}$ and $\alpha_{\mathrm{d}}$ are the coefficient related to the quality of recycled aggregate. Putting the values of $\alpha_{\mathrm{a}}$ and $\alpha_{\mathrm{b}}$ gotten from test results into the Equation (7), the value of $\alpha_{\mathrm{c}}$ and $\alpha_{\mathrm{d}}$ for the RCA has been determined to be 0.1 and 0.2 , resulting in the following equations:

$$
\begin{gathered}
\alpha_{\mathrm{a}}=0.53\left(1-0.1 \times r_{\mathrm{g}}\right) \\
\alpha_{\mathrm{b}}=0.2\left(1+0.2 \times r_{\mathrm{g}}\right)
\end{gathered}
$$

When RCA belongs to category II and the target compressive strength is below $50 \mathrm{MPa}$, Equation (8) can be used to determine $\alpha_{\mathrm{a}}$ and $\alpha_{\mathrm{b}}$ for RCAC. For other kinds of RCA, the value of $\alpha_{\mathrm{c}}$ and $\alpha_{\mathrm{d}}$ may be different, and the suitable value must be determined through the regression analysis of experimental data by Equation (7), then put $\alpha_{\mathrm{a}}$ and $\alpha_{\mathrm{b}}$ into Equation (6) to calculate the water-cement ratio.

\subsection{Water Content}

\subsubsection{Influence of Recycled Coarse Aggregate}

According to the experimental results in Table 6, the relation between the water content and slump of RCAC is shown in Figure 3. It can be seen that when $r_{\mathrm{g}}$ is kept constant, the slump of RCAC increases with the rise of water content. With the same water content, the slump of RCAC reduces with the increase of $r_{\mathrm{g}}$. This is because RCA has higher water absorption than NCA, and absorbs more water in concrete batching, which leads the reduction of effective water and the decreasing of slump. 


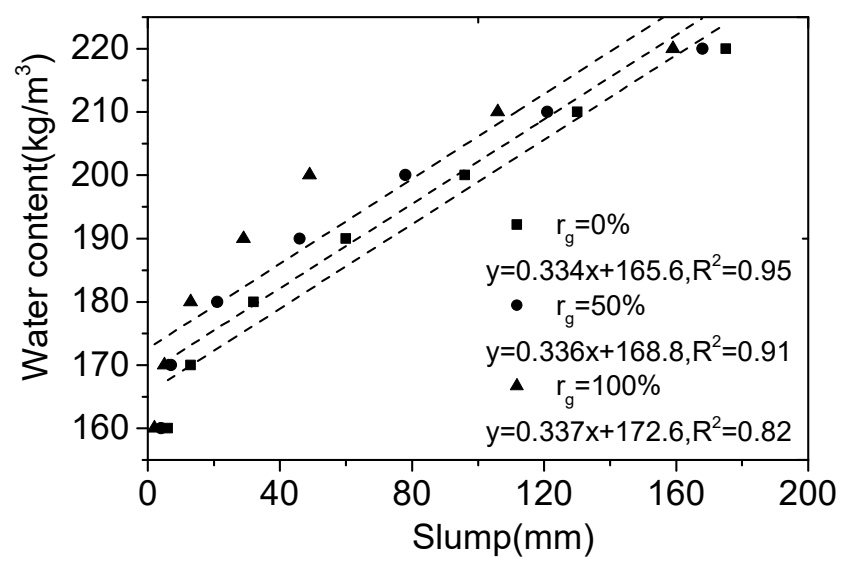

Figure 3. Relation between water content and slump of RCAC.

Generally, the water content is determined by the maximum size of coarse aggregate and the desired range of slump. In China, the water content of ordinary concrete is generally estimated through table look-up or calculated with equation as follows [39]:

$$
m_{\mathrm{w}}=3.33 \times(0.1 \times T+K)
$$

where $m_{\mathrm{w}}$ is the water content, $\mathrm{kg} / \mathrm{m}^{3} ; T$ is the desired slump, $\mathrm{mm} ; K$ is the constant determined by the type and maximum size of coarse aggregate. With the different type of aggregate, the value of $K$ can be obtained by test or look-up table, $K=53$ for the coarse aggregate of rubble with the maximum size of $20 \mathrm{~mm}$, and $K=48.5$ for the coarse aggregate of rubble with the maximum size of $40 \mathrm{~mm}$. It can be seen that the larger the particle diameter, the smaller the $K$ value.

Based on the test data in this paper, the formulas for water content can be obtained by regression and represented in Figure 3. It indicates the relation of water content with slump is a linear function for the SFRCAC with different $r_{\mathrm{g}}$, the slopes of these linear functions are similar, but the constant terms increase with the increasing of $r_{\mathrm{g}}$. Therefore, the relation between water content and slump can be expressed as follows:

$$
m_{\mathrm{w}}=3.33 \times\left(0.1 \times T_{0}+K_{\mathrm{g}}\right)
$$

where $T_{0}$ is the slump of RCAC; $K_{\mathrm{g}}$ is the parameter relative to the type and maximum size of coarse aggregate. According to the regression analysis of test data in this paper, $K_{\mathrm{g}}$ is obtained as 49.7, 50.7 and 51.8 for $r_{\mathrm{g}}$ of $0,50 \%$ and $100 \%$, respectively. $K_{\mathrm{g}}$ is no longer a constant like $K$ in Equation (9), but it increases with the increasing of $r_{\mathrm{g}}$. This is consistent with that the water content of RCAC increases with the increasing of $r_{\mathrm{g}}$. The difference of water absorption between RCA and NCA is an important factor affecting water content of RCAC. Hence, the calculation formula of $K_{\mathrm{g}}$ can be expressed as follows:

$$
K_{\mathrm{g}}=K\left[1+\left(\omega_{\mathrm{ra}}-\omega_{\mathrm{na}}\right) \times r_{\mathrm{g}}\right]
$$

where $\omega_{\text {ra }}$ is the water absorption of RCA; $\omega_{\text {na }}$ is the water absorption of NCA; $K$ is the constant depending on the type and maximum size of NCA, its value can be obtained by test or look-up table.

In this study, the value of $K$ is 49.7 from the test results, and $\omega_{\text {na }}=1.4 \%, \omega_{\text {ra }}=4.85 \%$, as shown in Table 1. Putting the value of these parameters into Equation (11), getting $K_{\mathrm{g}}=50.6$ for $r_{\mathrm{g}}=50 \%$ and $K_{\mathrm{g}}=51.4$ for $r_{\mathrm{g}}=100 \%$. The value of $K_{\mathrm{g}}$ with the different $r_{\mathrm{g}}$ calculated by Equation (11) was very close to the test results. Therefore, the water content of RCAC can be determined by Equations (10) and (11).

\subsubsection{Influence of Steel Fibers}

Based on the test results, the relation between the slump of SFRCAC and $V_{\mathrm{f}}$ can be seen in Table 7 . Obviously, the slump decreases with the increasing of $V_{\mathrm{f}}$. For each type of steel fiber, the slump of SFRCAC decreases with the increasing of $r_{\mathrm{g}}$. Due to the larger aspect ratio of HF, the slump reduction 
of RCAC with HF is much higher than that of MF, and has little to do with $r_{\mathrm{g}}$. Besides, the similar slump reduction was observed irrespective of the aggregate type.

The relation between the slump reduction ratio and the characteristic coefficient of steel fiber $\left(\lambda_{\mathrm{f}}\right)$ is shown in Figure 4, in which the points are drawn from the test results in this paper and previous literature [44]. Obviously, the slump reduction ratio is approximately linear with the characteristic coefficient of steel fiber, a formula can be determined based on the test results:

$$
T / T_{0}=1-0.38 \lambda_{\mathrm{f}}
$$

where $T$ is the desired slump of SFRCAC, mm; $T_{0}$ is the slump of the plain concrete which is corresponding to SFRCAC in same mixture proportion, $\mathrm{mm}$. When the desired slump of SFRCAC $(T)$ is determined, $T_{0}$ can be calculated by Equation (12), then using Equation (10), the water content of SFRCAC can be determined.

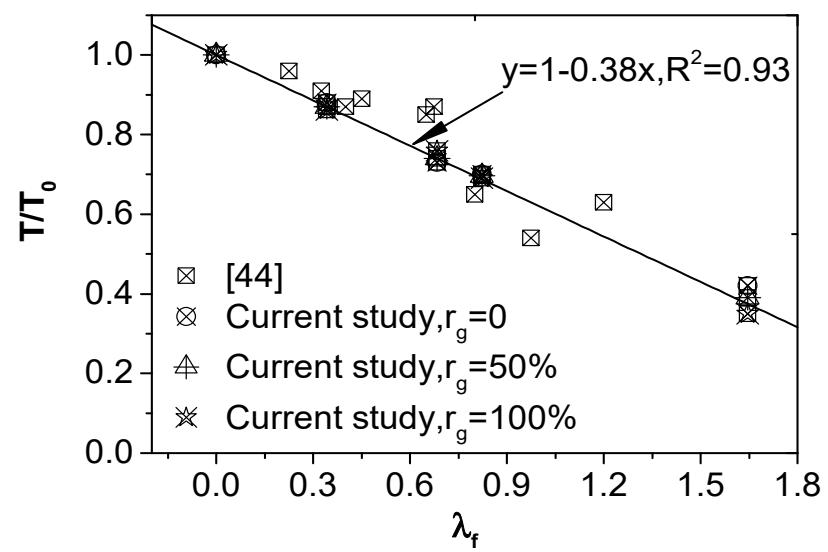

Figure 4. Relation between $T / T_{0}$ and $\lambda_{\mathrm{f}}$.

\subsection{Sand Ratio}

The test results by using the new sand content method determined by Equation (1) are shown in Table 7. It can be seen that sand ratio $\beta_{\mathrm{s}}$ increases regularly with the increasing of $V_{\mathrm{f}}$ and $r_{\mathrm{g}}$. For the SFRCAC with the same $V_{\mathrm{f}}, \beta_{\mathrm{s}}$ increases by $2.2 \%$ as $r_{\mathrm{g}}$ increases by $50 \%$. For the SFRCAC with the same $r_{\mathrm{g}}, \beta_{\mathrm{s}}$ increases by $0.7 \%$ as $V_{\mathrm{f}}$ increases by $0.5 \%$. This result is very close to that for the SFNCAC [45], where steel fiber was treated as part of the coarse aggregate used in sand ratio calculation, and it was concluded that $\beta_{\mathrm{s}}$ increases by $0.8 \%$ as $V_{\mathrm{f}}$ increases by $0.5 \%$.

In the test of this paper, the water content is kept constant, and the slump still decreases obviously with the increasing of $V_{\mathrm{f}}$ and $r_{\mathrm{g}}$ although the sand ratio increases with the increasing of $V_{\mathrm{f}}$ and $r_{\mathrm{g}}$. However, the slump in Table 7 using the new sand ratio method is much higher than that in Table 6, where the sand ratio was a constant of $36 \%$. The comparison of these test results is shown in Figure 5 . Obviously, the slump of SFRCAC using the new sand ratio method is much higher than that by using the old method, especially for SFRCAC with $r_{\mathrm{g}}$ of $100 \%$. This indicates that the workability of SFRCAC can be improved by using the new sand ratio method.

The comparison of measured compressive strength of SFRCAC designed by the new and old sand ratio method is shown in Figure 6. It can be seen from Figure 6 that for the SFRCAC with a constant of $r_{\mathrm{g}}$, its compressive strength increases with the increasing of $V_{\mathrm{f}}$. When $r_{\mathrm{g}}$ increases from 0 to $100 \%$, the compressive strength of SFRCAC designed by using the old sand ratio method decreases, but that designed by using the new sand ratio method increases slightly. For SFRCAC with $r_{\mathrm{g}}$ of $100 \%$, the difference of the compressive strength of SFRCAC designed by the new and old sand ratio method is more remarkable. 


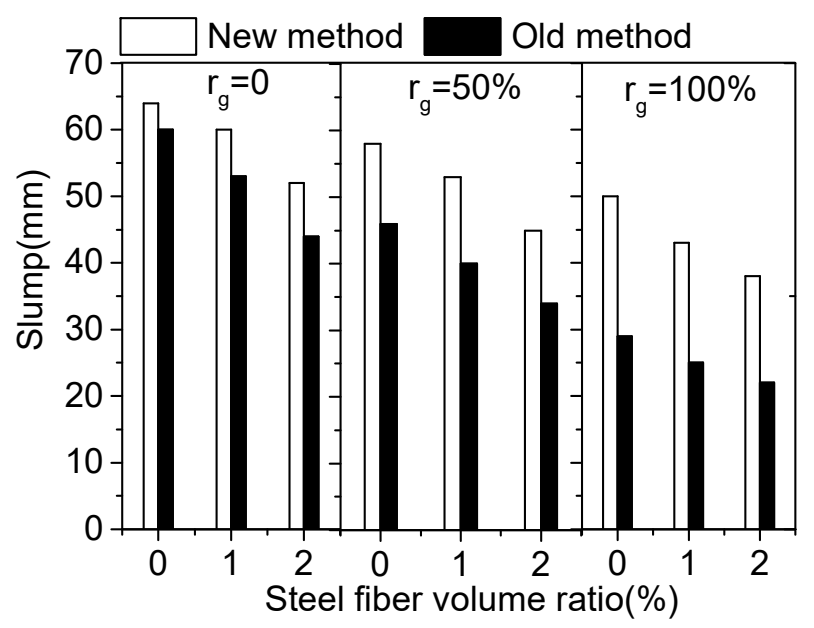

Figure 5. Comparison of slump by using different sand ratio method.

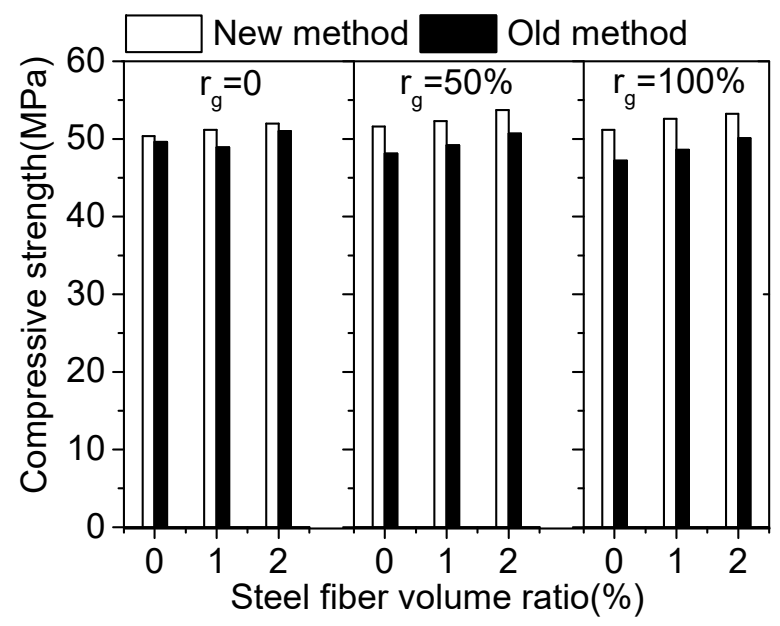

Figure 6. Comparison of compressive strength by using different sand ratio method.

\section{Experimental Verification}

In order to verify the mixture proportion design method was put forward in this paper, the specimens with the different dosages of RCA $\left(r_{\mathrm{g}}=0 \%, 50 \%, 100 \%\right)$ were used to achieve a desired compressive strength $\left(f_{\mathrm{cu}}=40 \mathrm{MPa}\right)$, flexural strength $\left(f_{\mathrm{ftm}}=10 \mathrm{MPa}\right)$, and slump $(T=50 \mathrm{~mm})$. The design process is shown as follows.

1. Determination of the steel fiber content Checking whether steel fiber is necessary or not. An empirical formula between the flexural strength and compressive strength for normal concrete [46] is used here, $f_{\mathrm{tm}}=0.89 \times\left(f_{\mathrm{c}}^{\prime}\right)^{0.5}$, where $f_{\mathrm{c}}^{\prime}$ is cylinder compressive strength and $f_{\mathrm{c}}^{\prime}=0.8 f_{\mathrm{cu}}$. The predicted value of $f_{\mathrm{tm}}=0.89 \times(0.8 \times 40)^{0.5}=5.03 \mathrm{MPa}$; since, $f_{\mathrm{tm}}<10 \mathrm{MPa}$ (the desired flexural strength), it is necessary to add the steel fiber to obtain the desired flexural strength.

2. Calculating the required content of steel fibers [Equation (5)] $\lambda_{\mathrm{f}}=\sqrt{\left(f_{\mathrm{ftm}} / f_{\mathrm{tm}}-\beta_{\mathrm{f}}\right) / \alpha_{\mathrm{f}}}=$ $\sqrt{(10 / 5.03-1) / 2.51}=0.63$ Since $\lambda_{\mathrm{f}}=V_{\mathrm{f}} l_{\mathrm{f}} / d_{\mathrm{f}}, V_{\mathrm{f}}=0.63 / 34.2=1.84 \%$ for MF; $V_{\mathrm{f}}=0.63 / 39.7=1.6 \%$ for WF; $V_{\mathrm{f}}=0.63 / 82.3=0.76 \%$ for HF.

3. Calculating the required W/C [Equations (6) and (8)] According to Equation (8), $\alpha_{\mathrm{a}}=0.53 \times(1-$ $\left.0.1 \times r_{\mathrm{g}}\right)$ and $\alpha_{\mathrm{b}}=0.2 \times\left(1+0.2 \times r_{\mathrm{g}}\right) ; \alpha_{\mathrm{a}}=0.53, \alpha_{\mathrm{b}}=0.2$ for $r_{\mathrm{g}}=0 ; \alpha_{\mathrm{a}}=0.503, \alpha_{\mathrm{b}}=0.22$ for $r_{\mathrm{g}}=50 \%$; $\alpha_{\mathrm{a}}=0.477, \alpha_{\mathrm{b}}=0.24$ for $r_{\mathrm{g}}=100 \% . f_{\mathrm{cu}, 0}$ is the prepared strength, $\sigma$ is the standard deviation of compressive strength. According to Chinese Standard [47], for the RCAC with $f_{\mathrm{cu}}=40 \mathrm{MPa}$, $\sigma=6 \mathrm{MPa}, f_{\mathrm{cu}, 0}=40+1.645 \times 6=50 \mathrm{MPa}$. According to Equation $(6), f_{\mathrm{cu}, 0} / f_{\mathrm{ce}}=\alpha_{\mathrm{a}} \times(\mathrm{C} / \mathrm{W}$ $\left.-\alpha_{\mathrm{b}}\right), \mathrm{C} / \mathrm{W}=1 /\left(f_{\mathrm{cu}, 0} / f_{\mathrm{ce}} / \alpha_{\mathrm{a}}+\alpha_{\mathrm{b}}\right)$, from Table $1, f_{\mathrm{ce}}=45 \mathrm{MPa}$, then: $\mathrm{W} / \mathrm{C}=1 /(50 / 45 / 0.53+$ 
$0.2)=0.43$, for $r_{\mathrm{g}}=0 ; \mathrm{W} / \mathrm{C}=1 /(50 / 45 / 0.503+0.22)=0.41$, for $r_{\mathrm{g}}=50 \% ; \mathrm{W} / \mathrm{C}=1 /(50 / 45 / 0.477$ $+0.24)=0.39$, for $r_{\mathrm{g}}=100 \%$.

4. Calculating the required water content [Equations (10)-(12)] According to Equation (11), $K_{\mathrm{g}}=K$ $\times\left[1+\left(\omega_{\text {ra }}-\omega_{\text {na }}\right) \times r_{\mathrm{g}}\right], K=49.7$. From Table $1, \omega_{\text {na }}=1.4 \%, \omega_{\text {ra }}=4.85 \% . K_{\mathrm{g}}=49.7 \times[1+(0.0485$ $\left.-0.014) \times r_{\mathrm{g}}\right], K_{\mathrm{g}}=49.7$ for $r_{\mathrm{g}}=0 ; K_{\mathrm{g}}=50.6$ for $r_{\mathrm{g}}=0 ; K_{\mathrm{g}}=51.4$ for $r_{\mathrm{g}}=100 \%$. According to Equation (12), $T / T_{0}=1-0.38 \lambda_{\mathrm{f}}, T_{0}=T /\left(1-0.38 \lambda_{\mathrm{f}}\right)=50 /(1-0.38 \times 0.63)=66 \mathrm{~mm}$. According to Equation $(10), m_{\mathrm{w}}=3.33 \times\left(0.1 T+K_{\mathrm{g}}\right)$, then $m_{\mathrm{w}}=3.33 \times(0.1 \times 66+49.7)=187.5 \mathrm{~kg}$, for $r_{\mathrm{g}}=0$; $m_{\mathrm{W}}=3.33 \times(0.1 \times 66+50.6)=190.5 \mathrm{~kg}$, for $r_{\mathrm{g}}=50 \% ; m_{\mathrm{w}}=3.33 \times(0.1 \times 66+51.4)=193 \mathrm{~kg}$, for $r_{\mathrm{g}}=100 \%$.

5. Calculating the required aggregate dosage [Equations (1)-(3)]. $r_{\mathrm{g}}=50 \%$ and WF was taken as an example to explain the calculation. From Table $1, P_{\text {na }}=44.3 \%, P_{\text {ra }}=50.3 \%, \rho_{\text {na }}=2814 \mathrm{~kg} / \mathrm{m}^{3}$, $\rho_{\text {ra }}=2640 \mathrm{~kg} / \mathrm{m}^{3}$; when $r_{\mathrm{g}}=50 \%, m_{\text {na }}=m_{\mathrm{ra}}, V_{\text {na }}=0.938 \times V_{\mathrm{ra}} ;$ According to Step $1, V_{\mathrm{f}}=1.6 \%$ for $\mathrm{WF}$; and then put these parameters in Equation (1), $V_{\mathrm{f}}=1.4 \times\left(0.443 \times 0.938 \times V_{\text {ra }}+0.503 \times V_{\text {ra }}\right.$ $+0.016)=1.286 \times V_{\mathrm{ra}}+0.0224$. According to Steps 2 and $3, r_{\mathrm{g}}=50 \%, \mathrm{~W} / \mathrm{C}=0.41, m_{\mathrm{W}}=190.5 \mathrm{~kg}$; therefore, $m_{\mathrm{C}}=m_{\mathrm{w}} /(\mathrm{W} / \mathrm{C})=464.6 \mathrm{~kg} ; V_{\mathrm{w}}=m_{\mathrm{w}} / \rho_{\mathrm{w}}=0.1905 \mathrm{~m}^{3}, V_{\mathrm{c}}=m_{\mathrm{c}} / \rho_{\mathrm{c}}=464.5 / 3100=0.15$ $\mathrm{m}^{3}$. According to Equation (2), $V_{\mathrm{c}}+V_{\mathrm{w}}+V_{\mathrm{s}}+V_{\mathrm{na}}+V_{\mathrm{ra}}+V_{\mathrm{f}}+\alpha=1 ; 0.15+0.1905+(1.286$ $\left.\times V_{\mathrm{ra}}+0.0224\right)+0.938 \times V_{\mathrm{ra}}+V_{\mathrm{ra}}+0.016+0.02=1, V_{\mathrm{ra}}=0.187, m_{\mathrm{ra}}=V_{\mathrm{ra}} \times \rho_{\mathrm{ra}}=493.7 \mathrm{~kg} ;$ $V_{\mathrm{s}}=1.286 \times V_{\mathrm{ra}}+0.0224=0.263, m_{\mathrm{s}}=V_{\mathrm{s}} \times \rho_{\mathrm{s}}=672.3 \mathrm{~kg}$.

Based on the established method, shown as above example, the mixture proportion details of SFRCAC are represented in Table 8 , and the relevant test results of compressive strength, flexural strength and slump of SFRCAC are shown in the identical table. It can be seen that all groups of SFRCACs have achieved the target compressive strength, flexural strength and slump.

Table 8. Mix design details of SFRCAC based on new method, test results of slump and compressive and flexural strength.

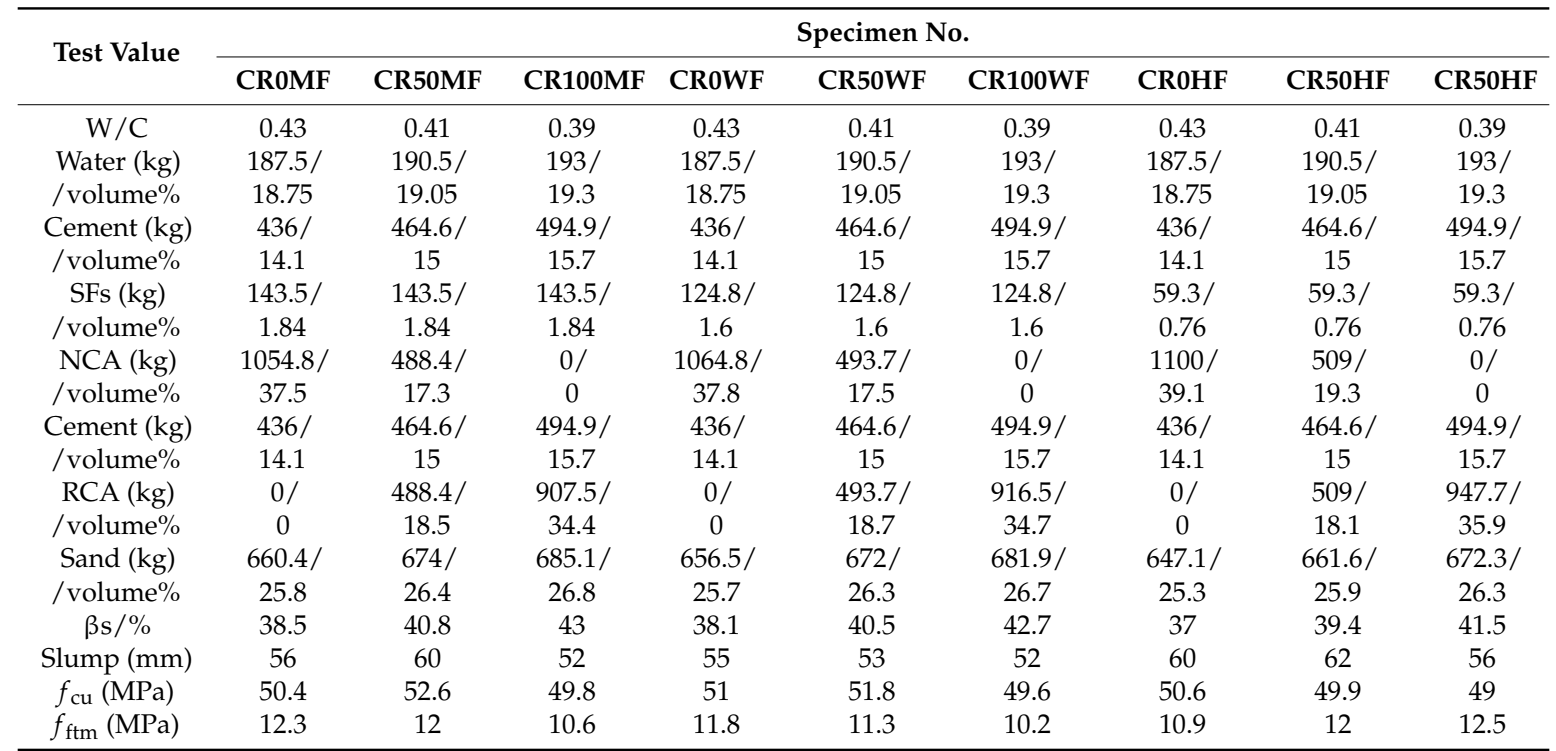

Note: CR50MF stands for the specimen with $r_{\mathrm{g}}$ of $50 \%$ and milling steel fiber.

\section{Conclusions}

Through the above analysis, the mixture design method of SFRCAC which is given the target compressive strength, flexural strength and slump is following:

1. The flexural strength of RCAC can be improved by adding steel fibers. The characteristic coefficient of steel fiber can be calculated by Equation (5). Once the steel fiber type is chosen, the steel fiber volume fraction can be determined. 
2. The calculation model of water-cement ratio for normal concrete can also be used in recycled concrete, except that the parameter $\alpha_{\mathrm{a}}, \alpha_{\mathrm{b}}$, which are connected with the quality of coarse aggregate and the replacement ratio $\left(r_{\mathrm{g}}\right)$, should be determined by test or calculated by Equations (6) and (7).

3. The water content of SFRCAC is related to replacement ratio $\left(r_{\mathrm{g}}\right)$ and characteristic coefficient of steel fiber $\left(\lambda_{\mathrm{f}}\right)$. According to the desired slump, the slump can be calculated by Equation (12). Then, the water content can be calculated by Equations (10) and (11).

4. The sand ratio $\left(\beta_{\mathrm{s}}\right)$ of SFRCAC is related to void fraction and apparent density of coarse aggregate, replacement ratio $\left(r_{\mathrm{g}}\right)$ and characteristic coefficient of steel fiber $\left(\lambda_{\mathrm{f}}\right)$. The volume fraction of steel fiber $\left(V_{\mathrm{s}}\right)$ can be calculated by Equation (1). Based on the material property of aggregates and steel fiber used in the test, $\beta_{\mathrm{s}}$ increases by a factor $2.4 \%$ when $r_{\mathrm{g}}$ is increased by $50 \%, \beta_{\mathrm{s}}$ increases by a factor $0.7 \%$ when $V_{\mathrm{f}}$ is increased by $0.5 \%$.

5. Due to the apparent density of RCA being generally less than that of NCA, the mass of RCAC is greatly influenced by apparent density and replacement ratio $\left(r_{\mathrm{g}}\right)$, the absolute volume method is recommended to be used to calculate the material component of the SFRCAC.

Author Contributions: Methodology, D.G. and L.Z.; Investigation, D.G. and L.Z.; Data Curation, L.Z.; Writing-Original Draft Preparation, L.Z.; Writing—Review \& Editing, M.N. and J.Z.; Funding Acquisition, D.G. and J.Z.

Funding: This work was part of a key project financially supported by National Natural Science Foundation of China (U1704254) and innovation team development plan of China's Ministry of Education (IRT_16R67).

Conflicts of Interest: The authors declare no conflict of interest.

\section{References}

1. Marie, I.; Quiasrawi, H. Closed-loop recycling of recycled concrete aggregates. J. Clean. Prod. 2012, 37, 243-248. [CrossRef]

2. Radonjanin, V.; Malešev, M.; Marinković, S.; Al Malty, A.E.S. Green recycled aggregate concrete. Constr. Build. Mater. 2013, 47, 1503-1511. [CrossRef]

3. Zhang, W.; Ingham, J.M. Using Recycled Concrete Aggregates in New Zealand Ready-Mix Concrete Production. J. Mater. Civ. Eng. 2010, 22, 443-450. [CrossRef]

4. Lim, W.F.; Chew, K.C.; Zayed, T.; Lee, Y.P.K.; Low, G.L.; Ting, S.K.; Ho, N.Y. Efficient Utilization of Recycled Concrete Aggregate in Structural Concrete. J. Mater. Civ. Eng. 2013, 25, 318-327.

5. De Juan, M.S.; Gutiérrez, P.A. Study on the influence of attached mortar content on the properties of recycled concrete aggregate. Constr. Build. Mater. 2009, 23, 872-877. [CrossRef]

6. Duan, Z.H.; Poon, C.S. Properties of recycled aggregate concrete made with recycled aggregates with different amounts of old adhered mortars. Mater. Des. 2014, 58, 19-29. [CrossRef]

7. Tam, V.W.Y.; Gao, X.F.; Tam, C.M.; Chan, C.H. New approach in measuring water absorption of recycled aggregates. Constr. Build. Mater. 2008, 22, 364-369. [CrossRef]

8. Medina, C.; Zhu, W.; Howind, T.; Sánchez De Rojas, M.I.; Frías, M. Influence of mixed recycled aggregate on the physical-Mechanical properties of recycled concrete. J. Clean. Prod. 2014, 68, 216-225. [CrossRef]

9. Erdem, S.; Dawson, A.R.; Thom, N.H. Microstructure-linked strength properties and impact response of conventional and recycled concrete reinforced with steel and synthetic macro fibres. Constr. Build. Mater. 2011, 25, 4025-4036. [CrossRef]

10. Gao, D.; Zhang, L.; Nokken, M. Mechanical behavior of recycled coarse aggregate concrete reinforced with steel fibers under direct shear. Cem. Concr. Compos. 2017, 79, 1-8. [CrossRef]

11. Carneiro, J.A.; Lima, P.R.L.; Leite, M.B.; Toledo Filho, R.D. Compressive stress-strain behavior of steel fiber reinforced-recycled aggregate concrete. Cem. Concr. Compos. 2014, 46, 65-72. [CrossRef]

12. Gao, D.; Zhang, L.; Nokken, M. Compressive behavior of steel fiber reinforced recycled coarse aggregate concrete designed with equivalent cubic compressive strength. Constr. Build. Mater. 2017, 141, 235-244. [CrossRef] 
13. Guo, Y.; Zhang, J.; Chen, G.; Xie, Z. Compressive behaviour of concrete structures incorporating recycled concrete aggregates, rubber crumb and reinforced with steel fibre, subjected to elevated temperatures. J. Clean. Prod. 2014, 72, 193-203. [CrossRef]

14. Senaratne, S.; Gerace, D.; Mirza, O.; Tam, V.W.Y.; Kang, W. The costs and benefits of combining recycled aggregate with steel fibres as a sustainable, structural material. J. Clean. Prod. 2016, 112, 2318-2327. [CrossRef]

15. Somna, R.; Jaturapitakkul, C.; Chalee, W.; Rattanachu, P. Effect of the Water to Binder Ratio and Ground Fly Ash on Properties of Recycled Aggregate Concrete. J. Mater. Civ. Eng. 2012, 24, 16-22. [CrossRef]

16. Etxeberria, M.; Vázquez, E.; Marí, A.; Barra, M. Influence of amount of recycled coarse aggregates and production process on properties of recycled aggregate concrete. Cem. Concr. Res. 2007, 37, 735-742. [CrossRef]

17. Meyer, C. The greening of the concrete industry. Cem. Concr. Compos. 2009, 31, 601-605. [CrossRef]

18. Liang, Y.; Ye, Z.; Vernerey, F.; Xi, Y. Development of Processing Methods to Improve Strength of Concrete with 100\% Recycled Coarse Aggregate. J. Mater. Civ. Eng. 2015. [CrossRef]

19. Tam, C.T.; Akbarnezhad, A.; Zhang, M.H.; Ong, K.C.G. Effects of the Parent Concrete Properties and Crushing Procedure on the Properties of Coarse Recycled Concrete Aggregates. J. Mater. Civ. Eng. 2013, 25, 1795-1802.

20. Butler, L.; West, J.S.; Tighe, S.L. Effect of recycled concrete coarse aggregate from multiple sources on the hardened properties of concrete with equivalent compressive strength. Constr. Build. Mater. 2013, 47, 1292-1301. [CrossRef]

21. Cui, H.; Shi, X.; Memon, S.A.; Xing, F.; Tang, W. Experimental Study on the Influence of Water Absorption of Recycled Coarse Aggregates on Properties of the Resulting Concretes. J. Mater. Civ. Eng. 2015. [CrossRef]

22. Ferreira, L.; de Brito, J.; Barra, M.; Abbas, A. Influence of the pre-saturation of recycled coarse concrete aggregates on concrete properties. Mag. Concr. Res. 2011, 63, 617-627. [CrossRef]

23. Tam, V.; Tam, C.M.; Wang, Y. Optimization on proportion for recycled aggregate in concrete using two-stage mixing approach. Constr. Build. Mater. 2007, 21, 1928-1939. [CrossRef]

24. Tam, V.; Gao, X.F.; Tam, C.M. Microstructural analysis of recycled aggregate concrete produced from two-stage mixing approach. Cem. Concr. Res. 2005, 35, 1195-1203. [CrossRef]

25. Fathifazl, G.; Abbas, A.; Razaqpur, A.G.; Isgor, O.B.; Fournier, B.; Foo, S. New Mixture Proportioning Method for Concrete Made with Coarse Recycled Concrete Aggregate. J. Mater. Civ. Eng. 2009, 21, 601-611. [CrossRef]

26. Pepe, M.; Toledo Filho, R.D.; Koenders, E.A.B.; Martinelli, E. A novel mix design methodology for Recycled Aggregate Concrete. Constr. Build. Mater. 2016, 122, 362-372. [CrossRef]

27. ACI. Removal and Reuse of Hardened Concrete, ACI 555-R01; ACI: Farmington Hills, MI, USA, 2001.

28. AQSIQ. Common Portland Cement, GB/175-2007; Standards Press of China: Beijing, China, 2007.

29. ASTM. Standard Specification for Concrete Aggregates, C33/C33M-13; ASTM International: West Conshohocken, PA, USA, 2013.

30. AQSIQ. Recycled Coarse Aggregate for Concrete, GB/T 25177; Standards Press of China: Beijing, China, 2010.

31. AQSIQ. Pebble and Crushed Stone for Construction, GB/T 14685; Standards Press of China: Beijing, China, 2011.

32. MOUHURD. Specification for Mix Proportion Design of Ordinary Concrete, JGJ 55-2011; China Construction Industry Press: Beijing, China, 2011.

33. Karadelis, J.N.; Lin, Y. Flexural strengths and fibre efficiency of steel-fibre-reinforced, roller-compacted, polymer modified concrete. Constr. Build. Mater. 2015, 93, 498-505. [CrossRef]

34. Gao, D.; Zhao, J.; Zhu, H. Design and Application of Steel Fiber Concrete; China Construction Industry Press: Beijing, China, 2002.

35. Saidani, M.; Saraireh, D.; Gerges, M. Behaviour of different types of fibre reinforced concrete without admixture. Eng. Struct. 2016, 113, 328-334. [CrossRef]

36. Kubissa, J.; Koper, M.; Koper, W.; Kubissa, W.; Koper, A. Water Demand of Concrete Recycled Aggregates. Procedia Eng. 2015, 108, 63-71. [CrossRef]

37. Dhinakaran, G.; Kumar, P.S. Effect of Admixed Recycled Aggregate Concrete on Properties of Fresh and Hardened Concrete. J. Mater. Civ. Eng. 2012, 24, 494-498.

38. Yazıc1, S.; İnan, G.; Tabak, V. Effect of aspect ratio and volume fraction of steel fiber on the mechanical properties of SFRC. Constr. Build. Mater. 2007, 21, 1250-1253. [CrossRef] 
39. Zhang, C.; Song, F.; Liu, F. Orial Handbooks of Building Construction; China Building Industry Press: Beijing, China, 2011.

40. AQSIQ. Standard for Test Method of Mechanical Properties on Ordinary Concrete, GB/T50081; China Architecture \& Building Press: Beijing, China, 2002.

41. ASTM. Standard Test Method for Flexural Performance of Fiber-Reinforced Concrete (Using Beam with Third-Point Loading), C1609; ASTM International: West Conshohocken, PA, USA, 2012.

42. Kim, H.; Kim, G.; Gucunski, N.; Nam, J.; Jeon, J. Assessment of flexural toughness and impact resistance of bundle-type polyamide fiber-reinforced concrete. Compos. Part B-Eng. 2015, 78, 431-446. [CrossRef]

43. Zega, C.J.; Di Maio, A.A. Recycled Concretes Made with Waste Ready-Mix Concrete as Coarse Aggregate. J. Mater. Civ. Eng. 2011, 23, 281-286. [CrossRef]

44. Tabsh, S.W.; Abdelfatah, A.S. Influence of recycled concrete aggregates on strength properties of concrete. Constr. Build. Mater. 2009, 23, 1163-1167. [CrossRef]

45. Zhao, S.; Du, H.; Qian, X.; Li, C. Study on direct mix design method for steel fiber reinforced high-strength concrete. China Civ. Eng. J. 2008, 41, 1-6.

46. CEB-FIP. Ceb-Fip Model Code 1990; Thomas Telford Ltd.: Lansanne, Switzerland, 1993.

47. MOHURD. Technical Specification for Application of Recycled Aggregate, JGJ/T 240-2011; China Construction Industry Press: Beijing, China, 2011.

(C) 2019 by the authors. Licensee MDPI, Basel, Switzerland. This article is an open access article distributed under the terms and conditions of the Creative Commons Attribution (CC BY) license (http://creativecommons.org/licenses/by/4.0/). 